\title{
Global Engineering Competencies and Cases
}

\section{Prof. Brent K Jesiek, Purdue University, West Lafayette}

Brent K. Jesiek is Assistant Professor in the Schools of Engineering Education and Electrical and Computer Engineering at Purdue University. He holds a B.S. in Electrical Engineering from Michigan Tech and M.S. and Ph.D. degrees in Science and Technology Studies (STS) from Virginia Tech. Dr. Jesiek draws on expertise from engineering, computing, and the social sciences to advance understanding of geographic, disciplinary, and historical variations in engineering education and professional practice.

\section{Qin Zhu, Purdue University}

Qin Zhu is a PhD student in the School of Engineering Education at Purdue University. His main research interests include global engineering education, engineering ethics, and philosophy of engineering and technology. He received his BS degree in material sciences and engineering and first $\mathrm{PhD}$ degree in philosophy of science and technology (engineering ethics) both from Dalian University of Technology (China).

\author{
Ms. Julia D Thompson, Purdue University, West Lafayette \\ Andrea Mazzurco \\ Prof. Sang Eun Woo, Purdue University
}




\section{Global Engineering Competencies and Cases}

Whether working on multi-national project teams, navigating geographically dispersed supply chains, or engaging customers and clients abroad, engineering graduates encounter worlds of professional practice that are increasingly global in character. This new reality poses challenges for engineering educators and employers, who are faced with the formidable task of preparing engineers to be more effective in diverse global contexts. In response, more global learning opportunities are being made available to engineering students, as reflected in gradual yet steady increases in the number of global engineering programs and participating students. ${ }^{1}$ Many companies are also offering professional development opportunities to help their employees learn foreign languages and cultures, cultural etiquette, and global leadership skills. Nonetheless, there remains a lack of clarity about what specific competencies are most important for global engineers, much less what training techniques best support development of such capabilities. These difficulties are further compounded by a large and diffuse body of literature discussing technical work practices in global context, including for engineers and other professionals.

In response to these challenges, this paper reports preliminary results of a comprehensive literature review focused on engineering in global context. The analyzed literature includes articles, papers, and reports drawn primarily from the fields of engineering education, business and management, organizational psychology, and human resources. The primary inclusion criteria for creating this collection centers on identifying descriptions of situations that involve: 1) a need for globally competent behaviors, 2) individuals from multiple national, regional, and/or ethnic cultures, and 3) technical tasks and/or problem solving. Particular emphasis is placed on finding case studies that provide detailed, practice-based accounts of global technical work, allowing us to identify specific kinds of situations, as well as associated contextappropriate behaviors.

We begin by discussing the background for our study, including a review of related literature and reasons for looking at global engineering from new and different angles. We then turn to a brief overview of our current data collection and analysis efforts, including interactions with subject matter experts, i.e., global engineers with industry experience. After reviewing some preliminary findings from our literature analysis, we conclude with a discussion of next steps, including how our research is being used to inspire creation of situational prompts and activities that can be leveraged for both assessment and instructional purposes. The audience for this paper includes engineering educators and representatives from industry who seek clarity regarding desirable attributes for global engineers. Additionally, many of the case studies and other materials discussed in this paper can potentially be used in existing training programs and courses.

\section{Background}

Since at least the late 1940s and early 1950s, commentators have discussed what kinds of capabilities and training are important for engineers tasked with working across countries and cultures. ${ }^{1}$ However, a variety of globalization trends, including intensified economic and technological competition among both countries and firms, have helped amplify these conversations in recent decades. The result has been a long string of commentaries and reports 
calling on educators to better prepare students in engineering and other STEM fields for the global realities they will likely face in their careers. ${ }^{2-7}$

These and many other reports and studies have also addressed questions about what specific kinds of attributes are important for the so-called "global engineer." For example, one forwardlooking NRC report published in 1999 outlined a "global engineering skill set" with four main items: "(1) language and cultural skills, (2) teamwork and group dynamic skills, (3) knowledge of the business and engineering cultures of counterpart countries, and (4) knowledge of international variations in engineering education and practice."3 Many other authors and groups have since compiled or created their own partially unique lists of attributes, and other efforts of this type are ongoing. ${ }^{9-22}$ Accreditation guidelines and curriculum reports stand as yet other important sources of evidence regarding the global dimensions of engineering practice. ${ }^{23-26}$

Wading into this large body of literature reveals two interrelated issues, the first methodological. There is considerable variability in how these lists of attributes have been developed, often accompanied by a lack of transparency and rigor. More specific shortcomings include a tendency among the leaders and authors of these initiatives to generate lists of attributes based on relatively weak sources of empirical data, including prior literature (which itself often lacks empirical grounding), the experiences of the authors themselves, and/or pre-existing learning outcomes from relevant courses or programs. In other instances, the stakeholders who are consulted to help generate such lists are not adequately characterized, making it difficult to evaluate their qualifications. Still other concerns include limited grounding in relevant theoretical frameworks (e.g., Bloom's Taxonomy), and little discussion of how certain attributes might be developed through specific types of learning experiences. Most of the studies cited above suffer from at least one or more of these faults.

A second kind of concern centers on the limited theoretical understanding around the attributes themselves. Most notably, there is often a lack of clarity regarding how the target attributes are defined, much less what they mean in practice. The literature offers many dozens of attributes and competencies, yet it is difficult to make sense of these existing documents due to differences in terminologies, theoretical foundations, and intended practical applications. The current state of engineering education literature calls for more systematic research that is grounded in theory and informed by extensive empirical data, including to address the following questions: what attributes are most important for global engineering, how are they related to one another, and how are they understood and experienced by students and practitioners?

Our research is addressing these issues in two ways. To begin, we acknowledge that the extant literature provides many valuable insights about what kinds of attributes are often viewed as important for global engineering practice, even if no widespread consensus has yet been reached. For the sake of conceptual clarity, we sort the existing lists of attributes into three major categories. ${ }^{27}$ The first category centers on foundational technical and professional attributes that are not explicitly global in nature, but are frequently viewed as important for most any practicing engineer, including engineering problem solving and design skills, communication and teamwork capabilities, etc. A second major category includes a variety of attributes that are viewed as important for most any global professional, such as foreign language proficiency, intercultural competence, a "global mindset," and appropriate cultural and historical knowledge. 
We distinguish and bracket these two categories based on a twofold rationale. First, there are already large and growing bodies of literature concerned with defining, developing, and assessing these attributes. Second, we call into question a longstanding tendency to view engineering practice as segmented, where the "technical core" is viewed separately from other knowledge, skills, attitudes, and abilities, including those global and professional in nature. ${ }^{28}$

This brings us to our third major domain of interest, global engineering competency, which we use as an umbrella term for those attributes and capabilities uniquely or especially relevant for engineering practice in global context. ${ }^{27} \mathrm{We}$ focus on this category since there is a considerable lack of literature in this area, which acknowledges that expertise - including that of engineers is often situated and domain-specific. For example, teamwork skill requirements may change when attention shifts from teams in general to engineering teams, and change yet again when looking at multicultural engineering teams. Recognition of such dynamics can be traced back to at least the aforementioned NRC report, which emphasized the importance of knowing about different "engineering cultures," including geographic variations in engineering education and practice. $^{8}$ As we discuss below, many reports and documents have discussed attributes that seem to fit within this category.

Nonetheless, there remain methodological questions about how one might go about identifying and validating what counts as "global engineering competency." Here we again acknowledge that considerable efforts have already been made to directly interrogate subject matter experts about what attributes they think are important for global engineers, primarily through surveys, interviews, and focus groups. However, this data often provides limited insights about what typical types of work situations challenge global engineers to perform specific kinds of contextappropriate behaviors, which themselves may require certain foundational attributes. To address this limitation, we begin by setting aside the question of what underlying competencies or attributes are most important for global engineers, and instead probe how experts actually experience global engineering practice. As our study methods indicate, this is in part accomplished through a search for case studies and other rich descriptions of global engineering practice, and in part through the kinds of critical incident interview and focus group techniques that are gaining considerable visibility and credibility in the engineering education literature. ${ }^{29}$ Systematically probing and identifying global engineering situations and behaviors can also help us establish essential foundations for other objectives, such as improving our understanding of what underlying competencies and attributes are important, developing related instructional materials, and creating new assessment instruments to measure global engineering competence.

\section{Study Design}

Our study design begins by asking: What types of work situations do global engineers typically encounter, and what kinds of context-appropriate behaviors are required in these situations? To address this question, we use two main sources of data: previously published literature, and direct interaction with subject matter experts (i.e., global engineers). To scope our data collection efforts, we specifically seek out descriptions of critical incidents, case studies, and other kinds of situations that involve: 1) a need for globally competent behaviors, 2) individuals from multiple national, regional, and/or ethnic cultures, and 3) technical tasks and/or problem solving. 
Our ongoing search for relevant literature has been wide-ranging, but with a particular focus on publications from engineering and other technical fields, business and management, and crosscultural studies. To date we have collected more than 50 relevant case studies from more nearly twenty different sources, including books, case study collections, and journal articles. The majority of the cases are based on actual, real-world situations, while others are hypothetical.

The research team has also conducted one-on-one and group (2-5 participant) interviews with 25 subjects. Most of these individuals hold one or more engineering degrees, and all have previous or current job roles involving global technical work, typically in large corporations. The data collection procedure involved first sensitizing interviewees to the domain of interest through discussion of a relevant global scenario prompt, presented as Figure 1 in the final section of this paper. The rest of the conversation utilized a critical incident approach to elicit stories of global engineering practice from participants. ${ }^{30}$ The interviewer's role was largely limited to probing for details and helping respondents understand what kinds of stories were most relevant. All data was collected following appropriate procedures for interacting with human subjects.

Our data analysis efforts involve development and application of a common coding framework for all of the cases and situations drawn from the literature and elicited from our research subjects. The categories and codes are being refined iteratively using both inductive and deductive approaches, which allow us to leverage our prior knowledge of the domain of interest as well as our growing familiarity with the collected data. The current categories include:

- National Cultures Involved: Including host location and culture, and guest culture(s).

- Situation-Motivation: The main reason or motivation for the situation or case, such as expatriate assignment, greenfield plant start-up, cross-national collaborative project, etc.

- Situation-Cultural Dimensions: Relevant cultural dimensions evident in the case, such as those drawn from Hofstede's work (e.g., power distance, individualism vs. collectivism, etc.) and/or other salient categories (e.g., nepotism, low vs. high context culture, etc.).

- Situation-Other Dimensions: Other salient dimensions evident in the case, including those related to global engineering competency (e.g., engineering cultures, ethics, etc.).

- Personal Attributes: Particular attributes or competencies explicitly mentioned as relevant or important for the case or situation described.

While data collection and analysis remains ongoing, we can report on three thematic dimensions coming out of our work, and particularly from our study of the extant case literature. We also discuss how our results are being leveraged to write questions for a new assessment instrument. Finally, it should be noted that this phase of the study allows us to discuss the kinds of situations and behaviors appearing most often in our data set, while future phases of research will involve clarifying the specific kinds of attributes that are most salient for these situations and behaviors.

\section{Preliminary Findings}

One important question emerging from our research centers on the extent to which the kinds of situations and behaviors evident in the case studies and critical incidents we have collected can be mapped to the various kinds of global capabilities presented in the lists of attributes reviewed 
above. The sections that follow address this question by focusing on what appear to be some key dimensions of global engineering competency that have surfaced in our data collection efforts.

\section{Technical Coordination}

The broadest and most prevalent category of situations and behaviors evident in our data set involve what Trevelyan calls "technical coordination," or "working with and influencing other people so they conscientiously perform some necessary work in accordance with a mutually agreed schedule." 31 This is perhaps not surprising given growing evidence that technical coordination is often the most prominent type of work performed by engineers. This usually involves informal rather than formal management tasks, and per Trevelyan may include activities such as: cooperating and coordinating with others both within and beyond the organization; supervising, monitoring, and reporting work progress, negotiating points of view; delegating work; team building and leading; networking; and developing policies and procedures.

Wading into the literature, we find that most of the cases presented by Acosta et al. in their Global Engineering text describe examples of technical coordination in cross-national/cultural context, including situations that involve working with others to design parts or tooling, diagnose and address problems, and implement new procedures or programs. ${ }^{32}$ Common underlying motivations for these situations include quality control, inventory control, supply chain and logistics, worker productivity, and expansion/relocation issues. To interpret the cultural dynamics of these situations, the authors utilize Hofstede's cultural dimensions. ${ }^{33}$ Many of the case studies and vignettes presented in Laroche's Managing Cultural Diversity in Technical Professions also involve technical coordination in the midst of cultural diversity, including in relation to supply chain issues, dealing with difficult customers and clients, working with nontechnical managers, and grappling with context-dependent styles of delegating, overseeing, and executing technical work. ${ }^{34}$ A Harvard Business Review case study by Yemen, on the other hand, examines Cisco Systems, Inc.'s move into China, focusing on both informal and formal management and leadership challenges in the context of a high-tech, multi-national firm. ${ }^{35}$

Yet to what extent are facets of cross-cultural technical coordination reflected in the lists of attributes reviewed above? While not explicitly described, professional capabilities in related areas such as communication, leadership, teamwork, and project management are sometimes mentioned. ${ }^{20}$ Other writers are more explicit about the cross-cultural dimensions of such attributes, as reflected in Mohtar and Dare's assertion that global engineers be able to "adapt to cultural norms in the professional arena and act appropriately," "communicate professionally in a culturally-appropriate manner," and "contribute to a culturally-diverse team." ${ }^{22}$ Ball et al. mention a number of similar attributes, with particular emphasis on multicultural teamwork. ${ }^{21}$ Allan and Chisholm's list of global competencies represents an especially well-developed set of attributes that are readily associated with technical coordination in global context, including a thoroughgoing emphasis on the importance of diversity awareness (including racial, cultural, ethnic, and linguistic) in relation to leadership, teamwork, and interpersonal communication competencies. These authors also note the importance of global engineers embracing "culturally appropriate relationship-centred [sic] involvement in the global environments in which they work" and "support[ing] in their job role culturally aware developments and practices.", 
A number of prior writings have also emphasized understanding and following global business norms and standards, as in Parkinson's discussion of the "international aspects of ... business practices," "Warnick's mention of "an ability to understand international business,"19 and Ball et al.'s reference to "basic principles of global businesses." ${ }^{21}$ Yet many of the materials we have reviewed to date focus instead on considerable contextual variations in management processes and professional conduct. For instance, cases by Acosta et al. and Shepherd help illustrate the difficulties and resistances that frequently emerge when organizations attempt to standardize corporate practices, processes, and values across disparate cultural contexts. ${ }^{32,36}$ Hence, it may be the case that the biggest difficulties facing engineers and other technical professionals center on cross-national differences in business practices rather than standards and commonalities.

Another relevant question centers on the extent to which an engineer's technical knowledge, skills, and abilities are germane to situations involving technical coordination. As Trevelyan has argued, coordination itself tends to be significantly non-technical, but nonetheless often requires considerable technical expertise and authority. We therefore acknowledge that some cases that involve technical coordination might appear as though the associated engineering issues or technical context are largely incidental. While we return to this issue below, the sections that follow highlight many cases where engineering or technical factors are pivotally important.

\section{Understanding and Negotiating Engineering Cultures}

A number of commentators and reports have emphasized the importance of global engineers understanding cross-national/cultural differences in the actual technical practices of engineers. As noted above, the $1999 \mathrm{NRC}$ report was prescient in this regard. More recent variations on this theme include statements stressing the importance of: "Applying engineering solutions and applications within a global context," "[A]nalyz[ing] how national differences are important in engineering work," 37 "Socio/political impact on problem definition,"12 and "Understand[ing] implications of cultural differences on how engineering tasks might be approached." "Extensive historical and ethnographic research by Downey and Lucena also highlights the significance of these issues. ${ }^{38}$ Yet to what extent do engineers encounter situations where differences in engineering cultures are salient to their work practices?

The literature reviewed thus far suggests such situations do occur. For example, Laroche's volume presents one case highlighting differences in Japanese and American understandings of technical standards, production quality, and organizational culture, and another case contrasting more theoretical versus practical approaches to technical problem solving among French and American engineers, respectively. ${ }^{34}$ Other cases from Laroche reveal cross-national differences in divisions of expert labor and expectations around the use of technical terms. Acosta et al. offer their own case contrasting differences in technical problem solving among French and Mexican production engineers. ${ }^{32}$ Still other cases help illustrate how aesthetic considerations - which are often deeply rooted in history and culture - come into play when technical experts come together to do design work, ${ }^{39}$ giving further credence to Parkinson's claim that engineers should "understand cultural differences relating to product design, manufacture and use."16

Even more generally, the specific processes used to solve technical problems may be culturally inflected, which can generate conflict and controversy. For instance, a case by Thomke and 
Nimgade discusses problems caused by different product development processes in Germany and India, while Hatvany and Pucik document considerable differences in decision-making processes in the U.S. and Japan. ${ }^{40-41}$ Additionally, Acosta et al. have discussed how widespread and often faulty - assumptions about "rational actor models" often influence strategic thinking and decision-making among Americans and many other Westerners, with significant implications for how technical work is coordinated and technical problems are approached. ${ }^{32}$ While the fundamentals of engineering science may be immutable across the globe, these cases provide considerable support for the argument that engineers trained and practicing in different parts of the world may often define and solve technical problems very differently. ${ }^{37}$

\section{Navigating Ethics, Standards, and Regulations}

There is also widespread recognition that practicing engineers should be aware that there are no universal, global expectations for what counts as ethical engineering practice. The ASCE, for instance, notes " $[t]$ he challenge of practicing ethically in a global environment," Parkinson argues that engineers should be prepared to "effectively deal with ethical issues arising from cultural or national differences." "Mohtar and Dare similarly stress "[t]he ability to make ethical and socially responsible decisions in the context of a culture divergent from my own," 22 while Ragusa emphasizes "moral responsibility to improve conditions and take action in diverse engineering settings." 42

Often intertwined with these themes are questions about standards and regulations, including the extent to which engineers are obligated to meet legal and other obligations prevailing in their home and/or host countries and cultures. Mohtar and Dare frame this issue in terms of "awareness of varying regulations, codes of practice, standards, technical specifications, testing/inspection procedures, environmental regulations, and systems of measurement between countries and regions," 22 while Patil notes the salience of "[i]nternational labor market and workplace imperatives." 10 Parkinson adds that global engineers should "[h]ave some exposure to international aspects of topics such as supply chain management, intellectual property, liability and risk, and business practices."16

The literature examined thus far reveals a number of cases related to these themes, including a handful drawn from engineering ethics textbooks. One of the more prominent ethical topics in this domain centers on gift giving and bribery, as illustrated through two cases by Humphreys focused on China, and a brief hypothetical scenario by Robinson et al. that does not specify a specific host country. ${ }^{43-44}$ Additionally, a chapter in an ethics textbook by Harris presents cases covering a wider variety of issues that cut across many geographic contexts, including lax pollution standards, corporate paternalism, nepotism, tax avoidance, workplace conditions, and employee remuneration. ${ }^{45}$ A multimedia case by Raju and Sankar, on the other hand, highlights the importance of global engineering standards, and explores issues of corporate and professional responsibility when problems surface in multi-national design projects. ${ }^{46}$ While most of these cases can be categorized as what Herkert calls "micro-ethical" situations, others emphasize "macro-ethical" issues, i.e., those involving larger questions of collective, social responsibility. ${ }^{47}$ Most notably, Vesilind and Gunn present cases involving human rights issues and environmental racism, while Lawrence and Tolley present a case focused on human rights concerns surfacing around infrastructure projects in the formerly authoritarian state of Myanmar. ${ }^{48-49}$ As suggested 
by this summary, there is strong evidence to suggest that cross-national differences in ethics, standards, and regulations represent an important facet of global engineering competency.

\section{Conclusions and Future Work}

While the areas discussed above have thus far emerged as most prominent in our data collection and analysis, additional domains and dimensions have also surfaced. For example, knowledge brokering and boundary spanning capabilities have been described in a handful of case studies, including Johri's research on global software engineers and DiMarco et al.'s study of global engineering project networks. ${ }^{50-51} \mathrm{We}$ will continue probing these areas in future work, possibly as additional sub-dimensions of technical coordination. Additionally, we still have much work to do in triangulating the literature reviewed above with the qualitative interview data we continue to collect and analyze. In doing so we intend to firm up our core domains of interest, including by identifying an expanded array of associated situations and behaviors.

Our efforts are also supporting another core project objective, namely generating a situational judgment test that can be used to evaluate 3-4 major dimensions of global engineering competency across multiple cultural contexts. Creating this multiple-choice assessment tool involves a systematic, iterative process of generating item stems and response options, in part inspired by the literature reviewed above and our interview data. Figure 1 presents a sample assessment question that was developed and piloted during the preliminary phases of this project. We expect the finished instrument will have 15-20 such questions. Further background details regarding use of scenario-based and situational approaches to assessment appear elsewhere. ${ }^{52}$

As an employee in a large multinational corporation, you are temporarily assigned to your company's branch operations in Shanghai, China. You are a member of a team consisting of three Chinese engineers, all about the same rank as you. Your team reports to an engineering manager, who is also Chinese. You are in a team meeting where your manager proposes a solution to a difficult quality control problem. However, you are concerned that the proposed solution will fail. Consider these possible actions:

a) Have the entire team approach the manager together.

b) Bring up your concerns in the meeting.

c) Set aside your concerns and follow the manager's lead.

d) Discuss the issue with the manager later, in a private meeting.

e) Consult your Chinese team members about appropriate actions to take.

f) Discuss your concerns with a higher-ranking manager.

Which of these actions (a-f) would you MOST likely take?

Which of these actions (a-f) would you LEAST likely take?

Figure 1. Sample Situational Assessment Question for Global Engineering Competency

This scenario largely falls within the domain of technical coordination, testing the extent to which respondents can pick both appropriate and inappropriate behavioral responses, including by drawing on prior cultural knowledge (e.g., understanding the concept of "saving face" in East Asian cultures) and aligned with their own levels of cultural sensitivity. We propose that placing a quality control issue at the heart of this scenario helps ground the situation in a salient technical context that is very familiar to engineers and other technical professionals. Our initial efforts to use this question as a discussion prompt in the context of global competency courses and 
workshops, as well as in individual and focus group interviews with subject matter experts, suggests that the scenario has the intended effect. Nonetheless, much work remains to create and validate a much larger set of questions falling squarely within the realm of global engineering competency, mirroring the types of real-world situations and behavioral expectations that global engineers frequently encounter in their work.

\section{Acknowledgments}

The authors gratefully acknowledge support for aspects of this work under National Science Foundation grant EEC-1160455, Global Engineering Competency: Definitions, Development Paths, and Situational Assessment. We also extend appreciation to other affiliates of the Global Engineering Education Collaboratory (GEEC) for their help on this project.

\section{References}

1 Jesiek, B. K., and Beddoes, K. From Diplomacy and Development to Competitiveness and Globalization: Historical Perspectives on the Internationalization of Engineering Education. In Downey, G. L. \& Beddoes, K. (Eds.), What is Global Engineering Education For?: The Making of International Educators (45-76). Morgan and Claypool, San Rafael, CA. 2010.

2 National Academy of Engineering and Office of International Affairs, National Research Council. Strengthening U.S. Engineering Through International Cooperation: Some Recommendations for Action. National Academy of Engineering, Washington, DC. 1987.

3 National Research Council. Engineering Education Tasks for the New Century: Japanese and U.S. Perspectives. National Academy Press, Washington, DC. 1999.

4 Katehi, L. The Global Engineer. In Educating the Engineer of 2020 (151-155). National Academy Press, Washington, DC. 2005.

5 Global Engineering Excellence Initiative (GEEI). In Search of Global Engineering Excellence: Educating the Next Generation of Engineers for the Global Workplace. Continental AG, Hanover, Germany. 2006.

6 Sigma Xi. Embracing Globalization: Assuring a Globally Engaged Science and Engineering Workforce (Workshop Report). Sigma Xi, Washington, DC. 2007.

7 Grandin, J., and Hirleman, E. D. Educating Engineers as Global Citizens: A Call for Action / A Report of the National Summit Meeting on the Globalization of Engineering Education. Online Journal of Global Engineering Education, 2009. 4(1): 1-28.

8 National Research Council. Engineering Education Tasks for the New Century: Japanese and U.S. Perspectives. National Academy Press, Washington, DC. 1999.

9 The Boeing Company and Rensselaer Polytechnic Institute (RPI). A Manifesto for Global Engineering Education: Summary Report of the Engineering Futures Conference, January 22-23, 1997. 1997.

10 Patil, A. Global Engineering Criteria for the Development of the Global Engineering Profession. World Transactions on Engineering and Technology Education, 2005. 4(1): 4952. 
11 Lohmann, J., Rollins, H., and Hoey, J. Defining, Developing, and Assessing Global Competence in Engineers. European Journal of Engineering Education, 2006. 31(1): 119131.

12 Allert, B., Atkinson, D., Groll, E., and Hirleman, E. D. Making the Case for Global Engineering: Building Foreign Language Collaborations for Designing, Implementing, and Assessing Programs. Online Journal for Global Engineering Education, 2007. 2(2): 1-14.

13 Sigma Xi. Developing Evaluation Approaches to International Collaborative Science and Engineering Activities (Workshop Report). Sigma Xi, Washington, DC. 2008.

Allan, M., and Chisholm, C. U. Achieving Engineering Competencies in the Global Information Society Through the Integration of On-Campus and Workplace Environments. Industry and Higher Education, 2008. 22(3): 145-152.

15 Parkinson, A., Harb, J., Magleby, S. Developing Global Competence in Engineers: What Does It Mean? What is Most Important? Proceedings of the 2009 ASEE Annual Conference and Exposition, Austin, TX, June 14-17, 2009.

16 Parkinson, A. The Rationale for Developing Global Competence. Online Journal of Global Engineering Education, 2009. 4(2): 1-15.

17 Grandin J. M., and Hedderich, N. Intercultural Competence in Engineering: Global Competence for Engineers. In Deardorff, D. K. (Ed.), The SAGE Handbook of Intercultural Competence (362-372). SAGE Publications, Inc., Thousand Oaks, CA and London. 2009.

18 Jesiek, B. K., Sangam, D., Thompson, J., Chang, Y., and Evangelou, D. Global Engineering Attributes and Attainment Pathways: A Study of Student Perceptions. Proceedings of the 2010 ASEE Annual Conference and Exposition, Louisville, KY, June 20-23, 2010. Warnick, G. M. Global Competence: Determination of its Importance for Engineers Working in a Global Environment. Educational Administration: Theses, Dissertations, and Student Research, Paper 35. University of Nebraska - Lincoln, Lincoln, NE. 2010. Available at http://digitalcommons.unl.edu/cehsedaddiss/35 2010 International Federation of Engineering Education Societies (IFEES). The Attributes of a Global Engineer Project. IFEES, Milwaukee, WI. 2013. Available at http://www.sefi.be/ifees/wp-content/uploads/WEEF-2012-Attributes-of-a-GlobalEngineer.pdf

21 Ball, A. G., Zaugg, H., Davies, R., Tateishi, I., Parkinson, A. R., Gensen, C. G., and Magleby, S. P. Identification and Validation of a Set of Global Competencies for Engineering Students. International Journal of Engineering Education, 2012. 28(1): 156-168.

22 Mohtar, R. H., and Dare, A. E. Global Design Team: A Global Service-Learning Experience. International Journal of Engineering Education, 2012. 28(1): 169-182.

23 ABET Engineering Accreditation Commission (EAC). Criteria for Accrediting Engineering Programs: Effective for Reviews During the 2012-2013 Accreditation Cycle. ABET, Inc., Baltimore, MD. 2011.

24 American Society of Civil Engineers (ASCE), Body of Knowledge Committee of the Committee on Academic Prerequisites for Professional Practice. Civil Engineering Body of Knowledge for the 21st Century: Preparing the Civil Engineer of the Future (Second Edition). American Society of Civil Engineers, Reston, VA. 2008.

25 Engineers Australia (EA). Guide to Assessment of Eligibility for Membership (Stage One Competency). Engineers Australia, Barton, ACT, Australia. 2010. 
European Network for Accreditation of Engineering Education (ENAEE). EUR-ACE

Framework Standards for the Accreditation of Engineering Programmes. ENAEE, Brussels, Belgium. 2008.

Johri, A., and Jesiek, B. K. Global and International Issues in Engineering Education. In Olds, B. M., and Johri, A. (Eds.), Cambridge Handbook of Engineering Education Research (CHEER). Cambridge University Press, Cambridge, UK. Forthcoming.

Lucena, J. What is Engineering for? A Search for Engineering beyond Militarism and Freemarkets. In Downey, G. L. \& Beddoes, K. (Eds.), What is Global Engineering Education For?: The Making of International Educators (361-383). Morgan and Claypool, San Rafael, CA. 2010.

29 Walther, J., Kellam, N., Sochacka, N., and Radcliffe, D. Engineering Competence? An Interpretive Investigation of Engineering Students' Professional Formation. Journal of Engineering Education, 2011. 100(4): 703-740. Flanagan, J. The Critical Incident Technique. Psychological Bulletin, 1954. 51: 327-358. Trevelyan, J. Technical Coordination in Engineering Practice. Journal of Engineering Education, 2007. 96(3): 191-204.

32 Acosta, C., Leon, V. J., Conrad, C., and Malave, C. O. Global Engineering: Design, Decision Making, and Communication. CRC Press, Boca Raton, FL. 2010.

33 Hofstede, G., and Hofstede, G. J. Cultures and Organizations: Software of the Mind (2nd Edition). New York: McGraw-Hill. 2005.

34 Laroche, L. Managing Cultural Diversity in Technical Professions. Butterworth-Heinemann, Burlington, MA. 2003.

35 Yemen, G., and Isabella, L. A. Cisco Switches in China: The Year of the Manager. Available at http://hbr.org/product/cisco-switches-in-china-the-year-of-the-manager/an/UV4292-PDFENG (accessed March 11, 2013)

36 Shephard, D. Case 1.3: Common Bond Values at the New Zealand Office of AT\&T. In Thomas, D. C. (Ed.), Readings and Cases in International Management: A Cross-Cultural Perspective (92-100). SAGE Publications, Inc., Thousand Oaks, CA and London. 2003. Downey, G., Lucena, J. C., Moskal, B., Bigley, T., Hays, C., Jesiek, B., Kelly, L., Lehr, J., Miller, J., Nichols-Belo, A., Ruff, S., and Parkhurst, R. The Globally Competent Engineer: Working Effectively with People Who Define Problems Differently. Journal of Engineering Education, 2006. 105(2): 107-122. Downey, G., and Lucena, J. Knowledge and Professional Identity in Engineering: CodeSwitching and Metrics of Progress. History and Technology: An International Journal, 2004. 20(4): 393-420.

39 Eccles, R. G., Edmondson, A. C., and Karadzhova, D. Arup: Building the Water Cube. Available at http://hbr.org/product/arup-building-the-water-cube/an/410054-PDF-ENG (accessed March 11, 2013)

40 Thomke, S., and Nimgade, A. Siemens AG: Global Development Strategy (A). Available at http://hbr.org/product/siemens-ag-global-development-strategy-a/an/602061-PDF-ENG (accessed March 11, 2013)

41 Hatvany, N., and Pucik, V. Case 1.7: Chiba International, Inc. In Thomas, D. C. (Ed.), Readings and Cases in International Management: A Cross-Cultural Perspective (115-122). SAGE Publications, Inc., Thousand Oaks, CA and London. 2003. 
Ragusa, G. Engineering Preparedness for Global Workforces: Curricular Connections and Experiential Impacts. Proceedings of the 2011 ASEE Annual Conference and Exposition, Vancouver, BC, Canada, June 26-29, 2011. Humphreys, K. What Every Engineer Should Know about Ethics. Marcel Dekker, Inc., New York, NY. 1999.

44 Robinson, S., Dixon, R, Preece, C., and Moodley, K. Engineering, Business, and Professional Ethics. Butterworth-Heinemann, Oxford, UK. 2007.

45 Harris, C. E., Jr., Pritchard, M. S., and Rabins, M. J. Engineering Ethics: Concepts and Cases (4th Edition). Wadsworth Publishing, Belmont, CA. 2009.

46 Raju, P. K., and Sankar, C. S. Mauritius Auditorium Design Case Study. Available at http://www.liteecases.com/lcm/catalog/case_stiudies/0/mauritius_auditorium_design $/ 5$ (accessed March 11, 2013)

47 Herkert, J. Professional Societies, Microethics, and Macroethics: Product Liability as an Ethical Issue in Engineering Design. International Journal of Engineering Education, 2003. 19(1): 163-167.

48 Vesilind, P. A., and Gunn, A. S. Hold Paramount: The Engineer's Responsibility to Society (Second Edition). Cengage Learning, Stamford, CT. 2011.

49 Lawrence, A. T., and Tolley, H. Jr. Case 1.2: Unocol and the Yadana Gas Pipeline Project. In Thomas, D. C. (Ed.), Readings and Cases in International Management: A Cross-cultural Perspective (75-91). Sage Publications, Thousand Oaks, CA. 2003.

50 Johri, A. Boundary Spanning Knowledge Broker: An Emerging Role in Global Engineering Firms. Proceedings of the 38th Annual Frontiers in Education Conference, Saratoga Springs, NY, October 25-28, 2008.

51 Di Marco, M. K., Taylor, J. E., Alin, P. Emergence and Role of Cultural Boundary Spanners in Global Engineering Project Networks. Journal of Management in Engineering, 2010. 26(3): 123-132.

52 Jesiek, B. K, and Woo, S. E. Realistic Assessment for Realistic Instruction: Situational Assessment Strategies for Engineering Education and Practice. Proceedings of the 2011 SEFI Annual Conference, Lisbon, Portugal. 2011. 